\title{
Uma análise quali-quantitativa das barragens do estado do Pará com dados do Sistema Nacional de Informações Sobre Segurança de Barragens (SNISB)
}

A preocupação com a segurança das barragens é crescente devido à importância social e os possíveis riscos ambientais serem em ampla escala, visivelmente constatados nos episódios de Mariana e Brumadinho. O Sistema Nacional de Informações sobre Segurança de Barragens registra 215 localizadas no estado do Pará, as quais serão objeto do estudo. O objetivo do trabalho é gerar uma análise quali-quantitativa focada na fiscalização e segurança das barragens no estado considerando as classificações por Dano Potencial Associado (D.P.A.) e por Categoria de Risco (C.R.). Os dados da pesquisa foram coletados na plataforma digita do SNISB, analisados segundo a Política Nacional de Segurança de Barragens, considerando as barragens paraenses não classificadas por D.P.A. e C.R. Obteve-se como resultado que $71,63 \%$ das barragens não estão classificadas quanto D.P.A. e $72,88 \%$ não tem classificação quanto ao C.R. As entidades fiscalizadoras das barragens citadas são a SEMAS/PA e o DNPM. Foram destacadas quatro barragens, em diferentes municípios, por seus volumes e pelo material tóxico e poluente que elas armazenam. Nesse sentido a ausência da classificação compromete o monitoramento e a segurança das barragens, pois por meio dessas informações é possível identificar a intensidade dos prováveis riscos para prevenir acidentes catastrófico.

\section{A quali-quantitative analysis of dams of state of Pará with data from the National Dam Safety Information System (SNISB)}

Concern about the safety of dams is growing due to their social importance and the possible environmental risks are considered on a large scale, clearly seen in the cases of Mariana and Brumadinho. The National Dam Safety Information System records 215 located in the state of Pará, as the objects of study. The objective of this work is to generate a qualitative and quantitative analysis focused on the supervision and safety of dams in the state, considering the statistics of Associated Potential Damage (D.P.A.) and Risk Category (C.R.). The survey data were collected on the SNISB digital platform, analyzed according to the National Dam Safety Policy, considering as paraense dams not classified by D.P.A. and C.R. Obtains a result that $71.63 \%$ of dams are not classified as D.P.A. and $72.88 \%$ are not classified by C.R. As dam inspectors mentioned are SEMAS / PA and DNPM. Four dams in different municipalities were highlighted for their volumes and the material in Mexico and pollutant they store. In this sense, the lack of classification compromises the monitoring and safety of dams, so this information can identify the intensity of the likely risks of catastrophic accidents.

Keywords: Dams in the State of Pará; Dam Inspection; SNISB.

Topic: Engenharia Geotécnica

Reviewed anonymously in the process of blind peer.

Maria Ilze da Silva Campos

Universidade da Amazônia, Brasil

http://lattes.cnpq.br/6492301649702966

http://orcid.org/0000-0002-6014-751X

ilze_campos@live.com
Received: 12/11/2019

Approved: 19/12/2019
Referencing this:

CAMPOS, M. I. S.. Uma análise quali-quantitativa das barragens do estado do Pará com dados do Sistema Nacional de Informações Sobre Segurança de Barragens (SNISB). Technology Science, v.2, n.1, p.5861, 2020. DOI: http://doi.org/10.6008/CBPC2674-6425.2020.001.0010 
Uma análise quali-quantitativa das barragens do estado do Pará com dados do Sistema Nacional de Informações Sobre Segurança de Barragens (SNISB)

\section{INTRODUÇÃO}

As barragens são estruturas de contenção com a capacidade de reter água, ou outro líquido, bem como rejeitos e detritos, para fins de armazenamento ou controle. A preocupação com a segurança das barragens é crescente devido à importância social e os possíveis riscos ambientais serem em ampla escala, visivelmente constatados nos episódios de Mariana e Brumadinho. Em 2010, foi sancionada a Lei 12.334 que estabelece a Política Nacional de Segurança de Barragens (PNSB) e cria o Sistema Nacional de Informações sobre Segurança de Barragens (SNISB), este último, com a finalidade de registrar, de modo informatizado, as condições de segurança de barragens em todo o território nacional. O sistema de classificação de barragens por categoria de risco (C.R.) e por dano potencial associado (D.P.A.) é um dos instrumentos da Política Nacional de Segurança de Barragens (PNSB).

A Agencia Nacional de Mineração (ANM) conceitua categoria de risco os danos que se referem aos aspectos próprios da barragem que podem influenciar na probabilidade de um rompimento, tais como: projeto construtivo, integridade da estrutura, estado de conservação, operação e manutenção e o plano de segurança. Já o dano potencial associado, segundo o SNISB, é o dano que pode ocorrer devido a rompimento, vazamento, infiltração no solo ou mau funcionamento de uma barragem, independentemente da sua probabilidade de ocorrência, podendo ser graduado de acordo com as perdas de vidas humanas e impactos sociais, econômicos e ambientais. O Brasil, por contar com vastos recursos hídricos e produção de minério, possui um número expressivo de barragens, existem 5099 barragens nos registros do SNISB das quais 215 estão no estado do Pará em que se concentra a pesquisa.

\section{METODOLOGIA}

Os dados para a elaboração do trabalho foram coletados na plataforma digital do SNISB e posteriormente analisados levando em consideração as barragens paraenses não classificadas por Dano Potencial Associado (D.P.A.) e por Categoria de Risco (C.R.), para caracterizar a entidade fiscalizadora, a finalidade da barragem e seu empreendedor. Também foram utilizados como instrumento de pesquisa a Lei 12.334 de 20 de setembro de 2010 - Política Nacional de Segurança de Barragens (PNSB), o site do Ministério do Meio Ambiente e o documento Perguntas e Respostas sobre Barragens de Mineração e o caso de Brumadinho da Agencia Nacional de Mineração (ANM). A partir dos quais criou-se uma tabela para melhor compreensão e visualização dos resultados e apresentação da análise proposta.

\section{RESULTADOS E DISCUSSÃO}

Das 215 barragens do estado do Pará, registradas no SNISB 154 barragens não estão classificadas quanto ao seu Dano Potencial Associado (D.P.A.), ou seja, 71,63\% não tem informações para caracterizar a intensidade dos danos que podem ocorrer devido rompimento, vazamento, infiltração no solo ou mau funcionamento da barragem, mesmo que não haja a possibilidade de ocorrência. Quanto a Categoria de Risco (C.R.) o número é maior, 161 barragens (72,88\%) não tem sua classificação registrada, pela C.R. não 
Uma análise quali-quantitativa das barragens do estado do Pará com dados do Sistema Nacional de Informações Sobre Segurança de Barragens (SNISB)

classificando em alto, médio ou baixo os aspectos que ocasionam os rompimentos. A SEMAS/PA, atualmente fiscaliza a maioria das barragens no estado, seguida por DNPM e ANEEL, nesta ordem, e é a entidade fiscalizadora com o maior número de barragens não classificadas.

Cada entidade fiscaliza as barragens de acordo com a sua finalidade, a ANEEL, Agência Nacional de Energia Elétrica, fiscaliza as barragens de geração de energia, o DNPM, Departamento Nacional de Produção Mineral, é a entidade fiscalizadora responsável pelas barragens destinadas a contenção de rejeitos minerais, e a SEMAS/PA, Secretaria do Estado de Meio Ambiente e Sustentabilidade do Pará, órgão ambiental estadual, fiscaliza as barragens de contenção de rejeitos industriais e as relacionadas a recursos hídricos em geral. A Tabela 01 a seguir mostrará a quantidade de barragens não classificadas de cada entidade fiscalizadora no estado do Pará.

Tabela 1: Barragens e suas Entidades Fiscalizadoras.

\begin{tabular}{|l|l|l|l|l|}
\hline Entidade Fiscalizadora & No de Barragens & \multicolumn{2}{|l|}{ Não Classificadas } & \multicolumn{2}{l|}{ Empreendedor cadastrado no SNISB } \\
\cline { 3 - 5 } & & D.P.A. & C.R. & \\
\hline SEMAS/PA & 85 & 78 & 85 & 0 \\
\hline DNPM & 76 & 76 & 76 & 0 \\
\hline ANEEL & 54 & 0 & 0 & 0 \\
\hline TOTAL & 215 & 154 & 161 & 0 \\
\hline
\end{tabular}

Fonte: SNISB - SISTEMA NACIONAL DE INFORMAÇÕES SOBRE SEGURANÇA DE BARRAGENS. Gráficos e Relatórios de Barragens Cadastrados no Sistema. ${ }^{1}$

Das barragens fiscalizadas pela SEMAS/PA duas foram destacas por seu volume e o material que elas armazenam, a barragem localizada no Município de Senador José Porfírio com 35,43300hm3 (hectômetros cúbicos) destinada a contenção de resíduos industriais e outra com a mesma finalidade, porém com volume de 40,0000 $\mathrm{hm}^{3}$ localizada na cidade de Barcarena. O DNPM, fiscaliza duas barragens que se sobressaem, uma no Município de Paragominas com volume de $104,03700 \mathrm{hm}^{3}$, e outra em Canaã dos Carajás com $80,53800 \mathrm{hm}^{3}$, ambas destinadas para contenção de rejeito de mineração.

É fundamental que essas, e outras, barragens tenham sua classificação quanto a D.P.A. e C.R., dado o risco que esses materiais poluentes e tóxicos oferecem. A ausência desses dados na plataforma do SNISB, que é um instrumento da PNSB compromete a realização de um monitoramento eficiente com base na observação do comportamento das barragens, logo ocasiona uma instabilidade na segurança das mesmas. Inviabilizando também a comunidade acadêmica e profissionais da área da Engenharia de barragens a obterem informações confiáveis para futuras pesquisas e atividades profissionais.

É possível constatar na tabela que nenhuma das barragens no estado do Pará, das registradas no SNISB, independente da entidade fiscalizadora, tem o seu responsável legal, Empreendedor, cadastrado. Portanto entidade fiscalizadora e empreendedor não estão em conformidade com suas obrigações expressas na Lei 12.334/2010 da Política Nacional de Segurança de Barragens.

\section{CONCLUSÕES}

\footnotetext{
${ }^{1}$ http://www.snisb.gov.br/portal/snisb 
Diante do estudo feito e da legislação, Lei 12.334/2010 - Política Nacional de Segurança de Barragens (PNSB), observou-se que manter o cadastro das barragens sob sua jurisdição, com identificação dos empreendedores, para fins de incorporação ao SNISB é atribuição do órgão fiscalizador, além de exigir do empreendedor o cadastramento e a atualização das informações relativas à barragem no sistema. Em observância com a mesma lei o empreendedor é o responsável legal pela segurança da barragem, e em seu artigo 17 dispõe sobre as suas obrigatoriedades, que entre elas está a de cadastrar e manter atualizadas as informações relativas à barragem no SNISB. A ausência de dados importantes como os de classificação do Dano Potencial Associado e da Categoria de Risco, que é um instrumento da PNSB, das barragens cadastradas do estado do Pará, compromete o monitoramento e a segurança das mesmas, pois a partir dos referidos dados é possível identificar a intensidade dos prováveis riscos que uma barragem tem de romper, de vazar ou penetrar no solo matérias poluentes e tóxicos para prevenir acidentes a nível catastrófico social, ambiental e econômico.

\section{REFERÊNCIAS}

BRASIL. Lei n. 12.334, 20 de setembro de 2010. Política Nacional de Segurança de Barragens. Brasília: DOU, 2010.

BRASIL. Ministério do Meio Ambiente. Segurança de Barragens. Brasília: MMT, 2019.
BRASIL. Agencia Nacional de Mineração. Perguntas e respostas sobre barragens de mineração e o caso de brumadinho. Brasília: ANM, 2019.

SNISB. Sistema Nacional de Informações Sobre Segurança de Barragens. Gráficos e Relatórios de Barragens Cadastrados no Sistema. Brasília: SNISB, 2019.

A CBPC - Companhia Brasileira de Produção Científica (CNPJ: 11.221.422/0001-03) detém os direitos materiais desta publicação. Os direitos referem-se à publicação do trabalho em qualquer parte do mundo, incluindo os direitos às renovações, expansões e disseminações da contribuição, bem como outros direitos subsidiários. Todos os trabalhos publicados eletronicamente poderão posteriormente ser publicados em coletâneas impressas sob coordenação da Sapientiae Publishing, da Companhia Brasileira de Produção Científica e seus parceiros autorizados. Os (as) autores (as) preservam os direitos autorais, mas não têm permissão para a publicação da contribuição em outro meio, impresso ou digital, em português ou em tradução. 